\title{
Seasonal Availability of Inoculum for Constriction Canker of Peach in New Jersey
}

\author{
N. Lalancette and D. M. Robison
}

Rutgers University, Agricultural Research and Extension Center, 121 Northville Road, Bridgeton, NJ 08302.

Current address of D. M. Robison: 113 Braun Dr., McMurray, PA 15317.

Accepted for publication 30 July 2001.

\section{ABSTRACT}

Lalancette, N., and Robison, D. M. 2001. Seasonal availability of inoculum for constriction canker of peach in New Jersey. Phytopathology 91:1109-1115.

The seasonal sporulation ability of Phomopsis amygdali was evaluated over a 2-year period by sampling twig cankers from commercial 'Encore' and 'Jerseyglo' peach orchards. Canker size, pycnidia per canker, percent pycnidia forming cirri, and spore production were evaluated once each month from January 1997 through December 1998. Average canker size and number of pycnidia per canker, which followed a sinusoidal pattern of change, were at lowest values in spring and at maximum values in fall. In 1997, the ability of pycnidia to sporulate (produce cirri) increased significantly from a minimum during winter to a maximum during sum- mer. In contrast, pycnidia sporulation in 1998 increased slowly throughout the year with a maximum in the fall. Inoculum potential, measured as number of spores per canker, peaked between June and August and was lowest in winter. Although pycnidia numbers in 1997 were about $50 \%$ of that observed in 1998, approximately twice as many conidia per canker were produced in 1997; consequently, the number of conidia produced per canker was equivalent in both years. These results indicated that $P$. amygdali acts as an $r$ strategist by maintaining abundant pycnidia and sporulation capability throughout much of the year. Therefore, infection is most likely not limited by the availability of inoculum.

Additional keywords: Fusicoccum canker, monocycle, Prunus persica.
The fungal plant pathogen Phomopsis amygdali (Del.) Tuset \& Portilla is the causal agent of constriction canker of peach, Prunus persica (18). In the Middle Atlantic region of the United States, this disease was originally thought to be caused by the fungus Fusicoccum amygdali $(8,18)$. However, taxonomic studies based on morphological characteristics indicated that the pathogen should be classified in Phomopsis (14). Furthermore, recent molecular examination of isolates from a similar disease in Georgia and South Carolina showed $P$. amygdali as the causal agent (4). Finally, the pathogen in canker specimens from a commercial New Jersey orchard has also been identified as P. amygdali (D. Farr, personal communication).

The pathogen infects peach shoots produced during the current season through fresh leaf scars in the fall and through bud scale scars, blossoms, and fruit scars during the following spring $(2,3,7)$. These infections result in the formation of reddish-brown elongate cankers that are centered at twig nodes. By the following summer, the cankers, now sunken and tan to silver in appearance, have completely girdled and killed the shoots. Because these shoots are the fruit bearing shoots for the current growing season, these canker infections result in a direct crop loss (10).

Sometime after infection, the pathogen begins the sporulation phase of its life cycle and produces pycnidia on the cankers. Once the initial pycnidia mature, they exude conidia in cirri during humid, wet weather. The conidia may infect new shoot growth, thereby perpetuating the epidemic. Pycnidia development and sporulation are believed to occur throughout the year, but no data are available to support these observations $(5,6)$. Consequently, the availability and seasonal distribution of inoculum are poorly understood. Information on these factors can have a direct impact

Corresponding author: N. Lalancette; E-mail address: lalancette@ aesop.rutgers.edu

Publication no. P-2001-0830-01R

(c) 2001 The American Phytopathological Society on the relative importance of the spring versus fall infection periods, as well as potential for infection during other times of the year.

The main objective of this study was to determine and describe the seasonal availability of inoculum. Specifically, interest was in determining if mature cankers, at any time of the year, contain viable pycnidia capable of producing spores under optimum conditions. Furthermore, because spore production is dependent on pathogen colonization of host tissue, canker expansion and pycnidia production were also studied over time. Finally, the relationship between air temperature and the ability of cankers to sporulate was investigated. Partial results of this study were previously reported (9).

\section{MATERIALS AND METHODS}

Canker sampling. Twig samples were obtained from two peach blocks, each located at the same commercial orchard, having a history of moderate to high incidence of constriction canker. The first block consisted of cv. Jerseyglo, whereas the second block consisted of cv. Encore. Samples were collected once per month from each cultivar block from January 1997 through December 1998.

During each monthly sample collection, six trees were arbitrarily selected from each cultivar block. On each tree, five cankers were cut for assessment. Thus, a total of 30 cankers per cultivar per month were collected over each of the 2 years. Because this study focused on availability of inoculum, only cankers having pycnidia (i.e., infectious cankers) were collected for assessment. Furthermore, this sample prerequisite eliminated the possibility of incorrectly assessing blossom blight cankers caused by Monilinia fructicola, because this pathogen does not produce pycnidia.

Air temperature data were obtained from a Solus datalogger (Solus Systems, Inc., Lake Oswego, OR) located approximately $8 \mathrm{~km}$ from the commercial test orchards. Temperature observa- 
tions were made every minute and recorded as hourly and daily averages. Topographic conditions at both sites, situated on a coastal plain, were similarly flat with sandy soil.

Canker size. To examine any change in the extent of fungal colonization by $P$. amygdali, the size and area of each canker were measured and calculated, respectively. Canker length (L), the distance between the furthest edges of the symptomatic tissue along the axis of the twig, was measured with a standard metric rule. Canker width (W), the circumference of the twig where the symptomatic tissue was the widest, was measured by a flexible seamstress tape. On most cankers, the width measurement was located near the center of the canker length, near the infection site at the node.

To calculate canker surface area, each canker was first classified as either elliptical or rectangular. This classification was based on an unraveled, two-dimensional view of the canker. Surface areas of cankers classified as rectangular were calculated as area $=\mathrm{L} \times \mathrm{W}$. Areas of elliptical cankers were calculated as area $=$ $\pi \times \mathrm{L} / 2 \times \mathrm{W} / 2$, in which the canker lengths and widths represented the major and minor axes of an ellipse, respectively. After all measurements, cankers were placed in a refrigerator overnight before continuing with pycnidia and sporulation assessments.

TABLE 1. Analysis of variance (ANOVA) of four characteristics that influence inoculum production of Phomopsis amygdali on peach for cultivar and year main effects and their interaction

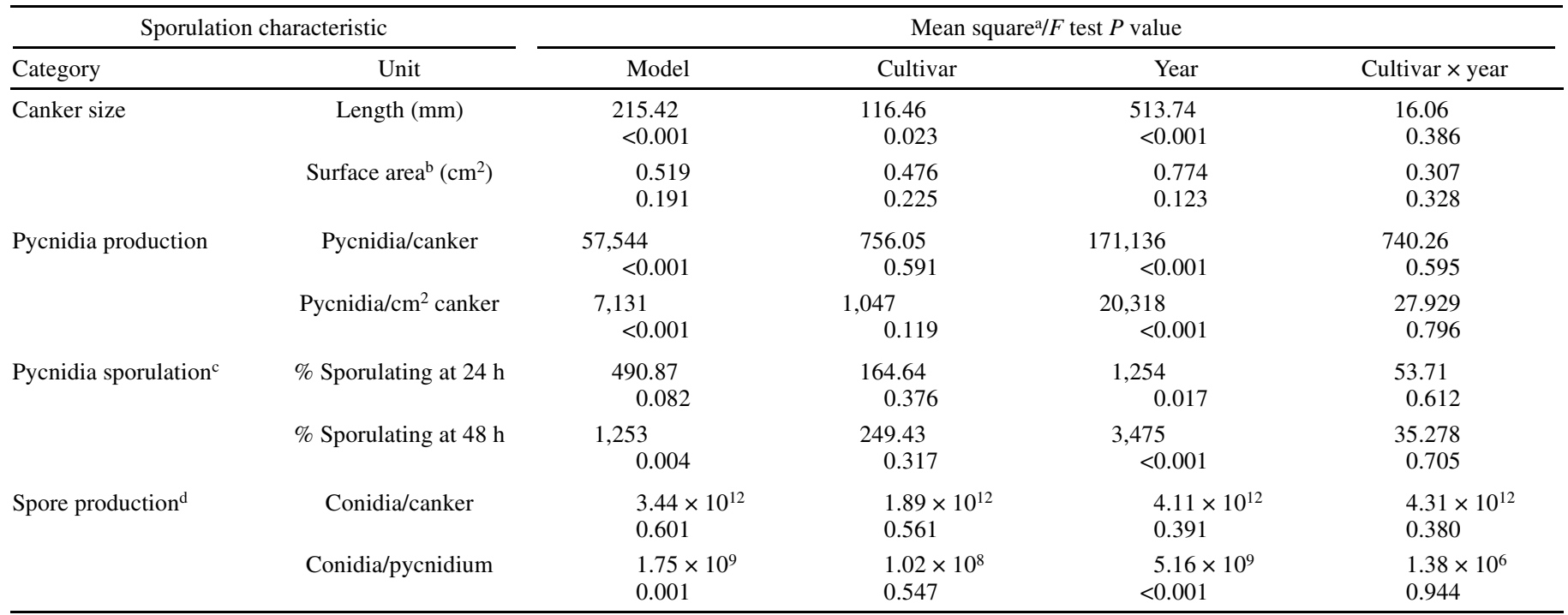

$\bar{a}$ Each ANOVA had a total of 48 degrees of freedom ( 2 years $\times 2$ cultivars $\times 12$ months/year).

${ }^{\mathrm{b}}$ Cankers were categorized as elliptical or rectangular based on a two-dimensional view. Area of rectangular cankers $=\mathrm{L} \times \mathrm{W}$; area of elliptical cankers $=\pi \times$ $\mathrm{L} / 2 \times \mathrm{W} / 2$, where the canker lengths (L) and widths (W) represented the major and minor axes of an ellipse, respectively.

${ }^{c}$ Percentage of pycnidia producing cirri on detached cankers after incubation for 24 and $48 \mathrm{~h}$ in total darkness at $20^{\circ} \mathrm{C}$ and $\geq 95 \%$ relative humidity.

${ }^{d}$ Alpha conidia numbers were estimated with a hemacytometer after cankers were incubated for $48 \mathrm{~h}$ in total darkness at $20^{\circ} \mathrm{C}$ and $\geq 95 \%$ relative humidity.

TABLE 2. Comparison of yearly means for each sporulation characteristic of Phomopsis amygdali on constriction cankers collected monthly from two commercial peach orchards

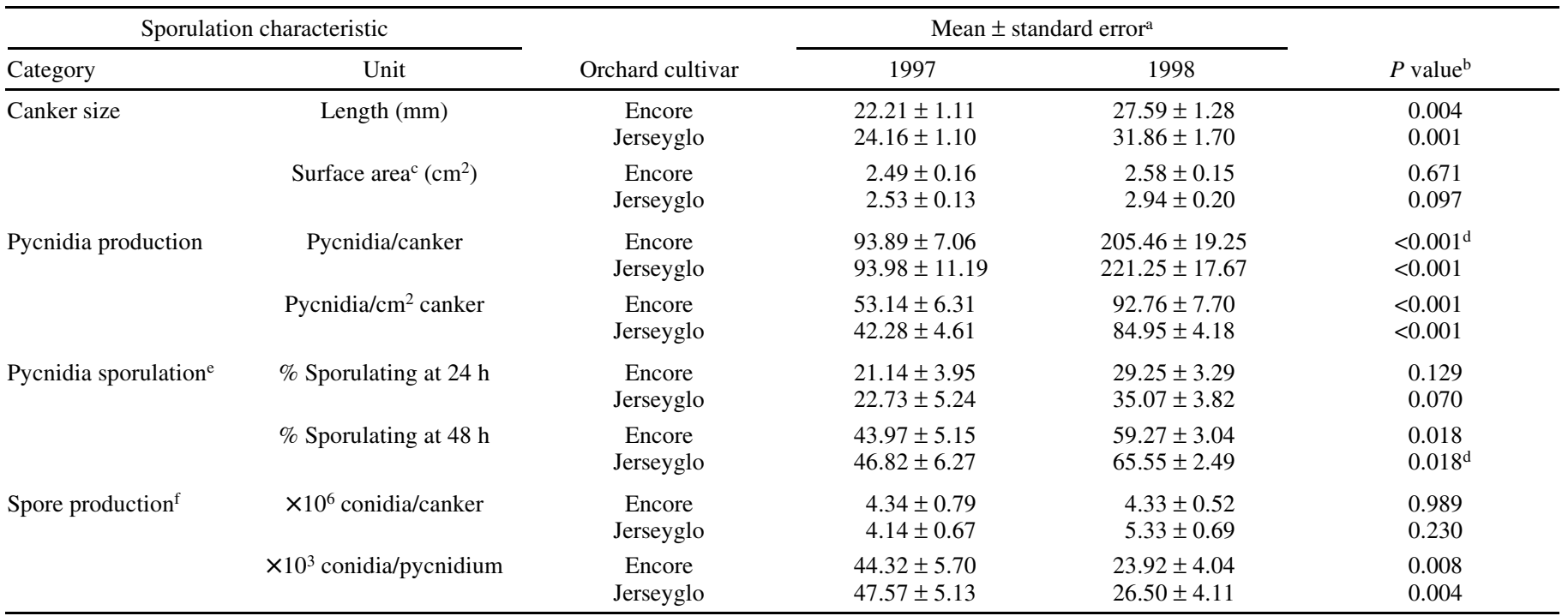

$\bar{a}$ Each yearly mean and standard error were calculated from monthly averages of 30 cankers.

${ }^{\mathrm{b}} t$ test for the null hypothesis that 1997 and 1998 means are equal; $n=12$ for each comparison.

${ }^{\mathrm{c}}$ Cankers were categorized as elliptical or rectangular based on a two-dimensional view. Area of rectangular cankers $=\mathrm{L} \times \mathrm{W}$; area of elliptical cankers $=\pi \times$

$\mathrm{L} / 2 \times \mathrm{W} / 2$, where the canker lengths (L) and widths (W) represented the major and minor axes of an ellipse, respectively.

${ }^{\mathrm{d}}$ Unequal sample variances required use of the Cochran approximate $t$ statistic.

${ }^{\mathrm{e}}$ Percentage of pycnidia producing cirri on cankers after incubation for 24 and $48 \mathrm{~h}$ in total darkness at $20^{\circ} \mathrm{C}$ and $\geq 95 \%$ relative humidity.

${ }^{\mathrm{f}}$ Alpha conidia numbers were estimated with a hemacytometer after cankers were incubated for $48 \mathrm{~h}$ in total darkness at $20^{\circ} \mathrm{C}$ and $\geq 95 \%$ relative humidity. 
Pycnidia production and sporulation. The number of pycnidia per canker and their ability to produce cirri was assessed for each canker. To simulate wetting from rainfall, the twigs were first soaked for $5 \mathrm{~min}$ in deionized water. After removal from the water, the twigs were immediately dried and placed in $3 \mathrm{~cm}$ deep plastic trays lined with moist paper towels to maintain high humidity. The covered trays were moved to an incubator maintained at $20^{\circ} \mathrm{C}$ and total darkness. A portable Hobo datalogger (Onset Computer Corp., Bourne, MA) placed inside a tray showed that this setup maintained $\geq 95 \%$ relative humidity.

After 24-h incubation, the trays were removed one at a time from the incubator for examination. Using a large $\times 10$ lighted magnifying lens or stereomicroscope at low power, the total number of pycnidia and the total number of sporulating pycnidia per canker were counted to the nearest multiple of five. A pycnidium was considered to be sporulating if any evidence of a cirrus was observed exuding from the ostiole. The pycnidia count was performed after incubation to allow for a more accurate determination of pycnidia numbers because they become more conspicuous upon water absorption. Pycnidia production was expressed as number of pycnidia per canker and as number of pycnidia per square centimeter of canker surface area.

After the 24-h assessment, the paper towels in the trays were remoistened if necessary and the cankers were returned to the trays for continued incubation at $20^{\circ} \mathrm{C}$. After $48 \mathrm{~h}$ from the initial wetting, the cankers were again assessed for number of sporulating pycnidia following the same procedure indicated for $24 \mathrm{~h}$. Pycnidia sporulation for both the 24 and $48 \mathrm{~h}$ data was expressed as percentage of pycnidia with visible cirri.

Spore production. The total number of alpha conidia produced was calculated for each sample of five cankers. Immediately after the 48-h pycnidia assessment, each canker was washed with water using an atomizer set at 5 psi (DeVilbiss Health Care, Inc., Somerset, PA). Conidia from all five cankers were bulk collected in a flask in which 1 to 2 drops of a dilute Tween 20 solution (1 drop of Tween 20 per liter of water) was added. After agitation, the concentration of conidia in each suspension was estimated by averaging the results of four hemacytometer chamber counts performed with a compound microscope. The total number of conidia produced per sample was then calculated from this concentration estimate and the total volume of the suspension. Any beta conidia that were observed, a rare occurrence, were not included in the assessment. Given these data, spore production was expressed as the number of conidia per canker and as the number of conidia per pycnidium.

Statistical analysis. To examine the overall effect of cultivar and year factors on each sporulation characteristic, separate analyses of variance (ANOVA) were performed on each dependent variable using the SAS ANOVA procedure (SAS Institute Inc.,
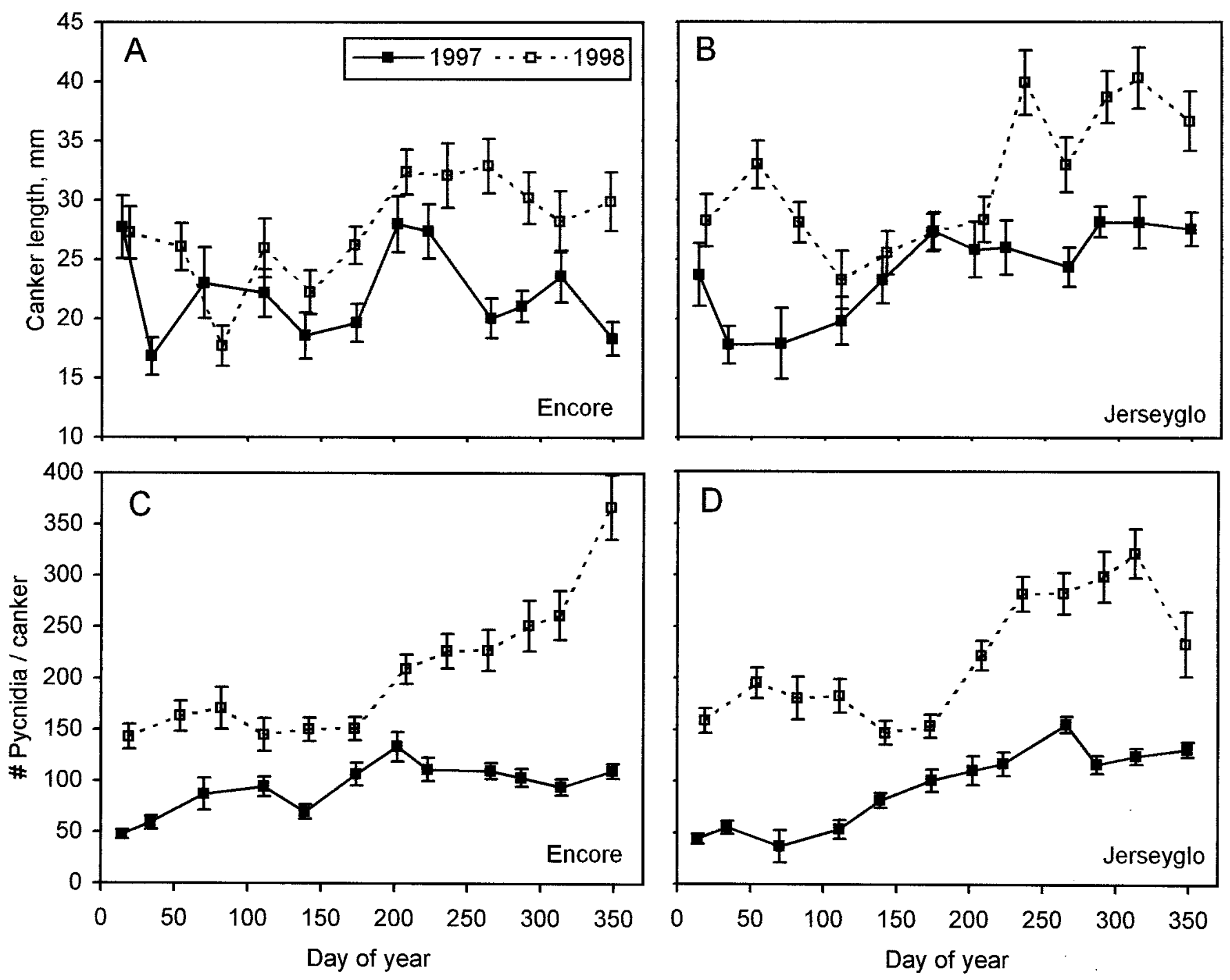

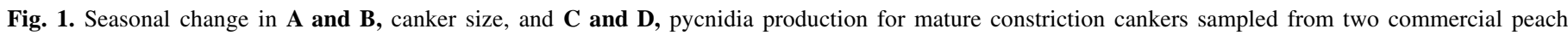

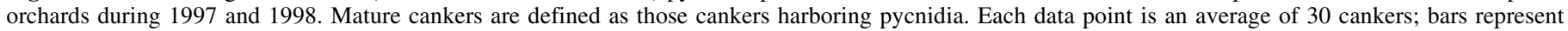
standard error of the mean. 
Cary, NC). Yearly means for each combination of cultivar and dependent variable were compared by the SAS TTEST procedure. Seasonal changes or trends over time were examined graphically by plotting each dependent variable against day of year.

The correlation between air temperature and sporulation ability, assessed as the average number of conidia per canker, was examined by the SAS CORR procedure. Three different temperature variables were examined for their correlation with sporulation ability: means of hourly air temperature data for the 1-, 2-, and 4-week periods preceding the date of canker collection. Linear and nonlinear monotonic associations were determined by calculating Pearson and Spearman rank correlation coefficients, respectively.

\section{RESULTS}

Canker size. When canker size was expressed as canker length, both main effects were significant in the ANOVA results, indicating significant differences between cultivars and years (Table 1). Specifically, average canker lengths in 1998 were significantly greater than in 1997 for both Encore and Jerseyglo cultivars, evidenced by the low $P$ values for the $t$ test comparisons (Table 2). However, neither of the main effects was significant for the canker surface area dependent variable (Table 1), and yearly means for each cultivar were not significantly different (Table 2).
'Jerseyglo' canker lengths and surface area means were larger than those of cv. Encore in both years.

The general graphical pattern of canker length over time appeared sinusoidal (Fig. 1A and B). Except for the 1997 'Encore' data, the shortest mature canker lengths were observed between days 50 and 200, whereas the longest lengths were recorded after day 200. Lengths during the second half of the year were, on average, 5 to $10 \mathrm{~mm}$ longer than observed during the earlier portion of the year. However, short mature cankers harboring pycnidia, at less than $50 \%$ final length, were not observed on either cultivar in either year. Average monthly canker length was consistently shorter in 1997 than in 1998 for both cultivars.

Pycnidia production. Results of ANOVA indicated that the two cultivars did not differ significantly in either pycnidia production variable; however, the year main effects were highly significant for both dependent variables (Table 1). Furthermore, individual 1997 and 1998 year averages for each of the four combinations of cultivar and dependent variables were significantly different with very low $P$ values $(P<0.001)$ (Table 2$)$. The mean number of pycnidia per canker in 1998 ranged from 2.2 (Encore) to 2.4 (Jerseyglo) times that observed in 1997. Similarly, mean pycnidia density in 1998 was about twice that observed in 1997, ranging from 1.7 (Encore) to 2.0 (Jerseyglo) times as many pycnidia per unit area of canker.
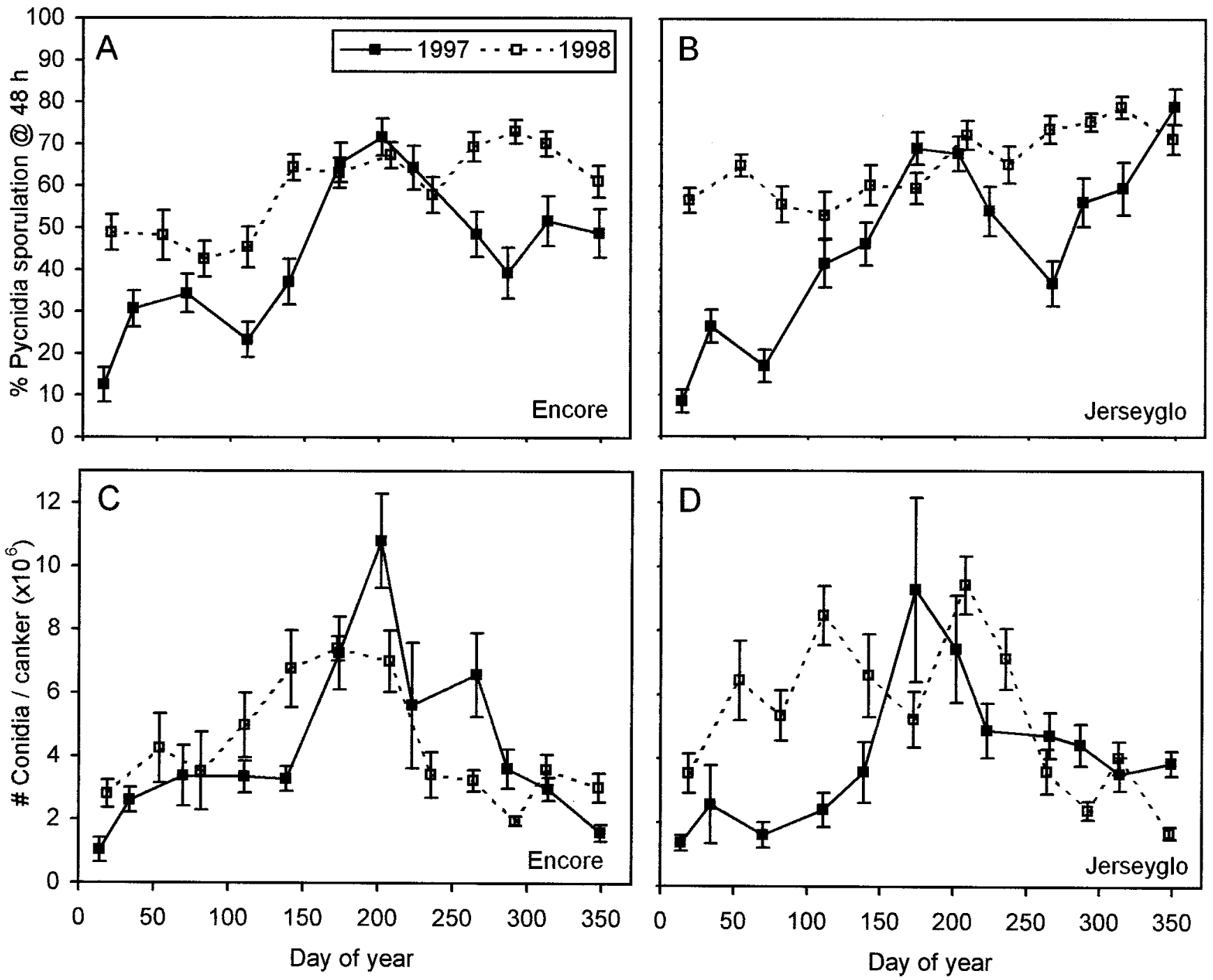

Fig. 2. Seasonal change in $\mathbf{A}$ and $\mathbf{B}$, sporulation ability of pycnidia, and $\mathbf{C}$ and $\mathbf{D}$, spore production for mature constriction cankers sampled from two commercial peach orchards during 1997 and 1998. Mature cankers are defined as those cankers harboring pycnidia. Both pycnidia sporulation (those pycnidia producing visible cirri) and alpha conidia production were assessed after cankers were incubated for $48 \mathrm{~h}$ at $20^{\circ} \mathrm{C}$ and $\geq 95 \%$ relative humidity. Each data point is an average of 30 cankers; bars represent standard error of the mean. 
In general, the number of pycnidia per canker followed a temporal pattern similar to that observed for canker length (Fig. 1C and D). Low numbers of pycnidia were observed earlier in the year between days 50 and 200 when cankers were shorter. Similarly, the highest counts of pycnidia per canker were recorded toward the end of the season when a greater proportion of larger mature cankers was observed in the population. However, the fewest number of pycnidia per canker was observed in January when cankers were relatively small but greater than their minimum size.

Pycnidia sporulation. ANOVA of percent pycnidia sporulation after 24-h incubation revealed a nonsignificant $F$ value for the overall mean square of the model (Table 1). Although the year main effect for this dependent variable was significant at $P=$ 0.017, individual $t$ test comparisons for each cultivar showed that 1997 and 1998 means were not statistically different (Table 2). ANOVA of percent sporulating pycnidia at $48 \mathrm{~h}$ resulted in a significant $F$ value for the overall model mean square (Table 1). The year main effect was highly significant at $P<0.001$, and 1998 means for each cultivar were statistically greater than those obtained in 1997 (Table 2). In 1998, 15.3 and 18.7\% more pycnidia sporulated on average than observed in 1997 for cvs. Encore and Jerseyglo, respectively.

The seasonal pattern of pycnidia sporulation was similar for both cultivars in each year; however, a significant difference in the pattern was evident when comparing years for each cultivar (Fig. 2A and B). The 1997 data showed a maximum ability of pycnidia to produce cirri during the middle of the year, from days 150 to 250 (30 May to 7 September); a second increase in sporulation ability appeared to occur at the end of the year, particularly for cv. Jerseyglo. In contrast, the 1998 data depicted a season-long increase in sporulation ability, with maximum percent pycnidia sporulation occurring near the end of the year between days 250 and 300 (7 September and 27 October). In both years, the lowest percent pycnidia sporulation occurred early in the year. However, in 1997, these minimums were at approximately $10 \%$ sporulation, whereas in 1998, they were considerably higher with approximately 45 to $55 \%$ of the pycnidia producing cirri.

Spore production. Based on ANOVA, the number of alpha conidia produced per canker was not significantly different between cultivars or years (Table 1). Consequently, no differences in this dependent variable were observed in the $t$ test comparisons between yearly means for both cvs. Encore and Jerseyglo (Table 2). However, when spore production was calculated on a per pycnidium basis, highly significant mean squares occurred for the overall ANOVA model and year main effects (Table 1). On average, the number of conidia per pycnidium was 1.9 and 1.8 times greater in 1997 than it was in 1998 for cvs. Encore and Jerseyglo cankers, respectively (Table 2).

The number of conidia produced per canker was greatest during the middle of the year, with maximum spore production observed between days 170 and 210 (Fig. 2C and D). This timing agreed with the observed maximum pycnidia sporulation observed in 1997 (Fig. 2A and B). On cv. Encore, time of peak conidia formation occurred on days 202 (21 July) and 173 (22 June) in 1997 and 1998, respectively. On cv. Jerseyglo, the maximum number of conidia per canker occurred on days 174 (23 June) and 208 (27 July) in 1997 and 1998, respectively. The level of maximum spore production was similar across both years and cultivars, ranging from 7.4 to $10.8 \times 10^{6}$ conidia per canker. The lowest levels of spore production, ranging from 1.0 to $3.9 \times 10^{6}$ conidia per canker, occurred in December and January.

Temperature association. Of the three temperature variables examined, the best overall correlation was obtained with the 2-week temperature means. Graphs of these means coincided with those showing canker sporulation ability, particularly for the 1997 season (Figs. 2C and D and 3). Peak temperatures and sporulation were observed during summer, whereas the lowest values occur- red during the winter. In 1997, sporulation ability was highly and significantly correlated with the 2-week temperature means (Fig. 4). Scatter plots for both cultivars showed a nonlinear relationship that was also evident from the slightly higher Spearman coefficients. In contrast, scatter plots for the 1998 data did not indicate any association between variables for either cultivar (Fig. 4). Regardless of the temperature variable examined, correlation coefficients were considerably lower and none were significant.

\section{DISCUSSION}

The amount and timing of inoculum production by any plant pathogen are crucial factors that determine the pathogen's ability to initiate and maintain epidemics, particularly across growing seasons. One successful approach employed by $K$ strategist fungal pathogens involves accurate timing of a limited amount of spores, or in general, a high inoculum efficacy coupled with a low initial inoculum level (17). This approach is exemplified by the teleomorph Venturia inaequalis, causal agent of apple scab. This pathogen produces pseudothecia that mature and release a fixed-number of ascospores during a 5- to 9-week period in spring when foliage and fruit are highly susceptible (1). In contrast, the results of this experiment clearly indicated that $P$. amygdali on peach acts as an $r$ strategist by having the ability to produce inoculum in copious quantities throughout much of the year. Although the infection efficiency and survival of $P$. amygdali alpha conidia are not known, this approach more than likely insures that sufficient inoculum is available during fall leaf-drop and spring bud-break periods of susceptibility.

The size of mature constriction cankers, defined as those cankers harboring pycnidia, oscillated in a sinusoidal pattern. Average canker size was smallest in late winter and early spring and largest in late summer and early fall. This periodic pattern was most likely a reflection of infection during the fall and spring periods of susceptibility. The infection in the fall produced cankers that began forming pycnidia the following spring. Because these now mature cankers were still small, their inclusion in the sample reduced the overall mean. However, the fall-initiated cankers and those resulting from spring infections grew more rapidly during the subsequent warm summer months, producing large cankers by the following fall. This same rapid expansion also resulted in the highest level of pycnidia per canker during late summer and fall. Indeed, the pattern of pycnidia production over time was very similar to that observed for canker expansion.

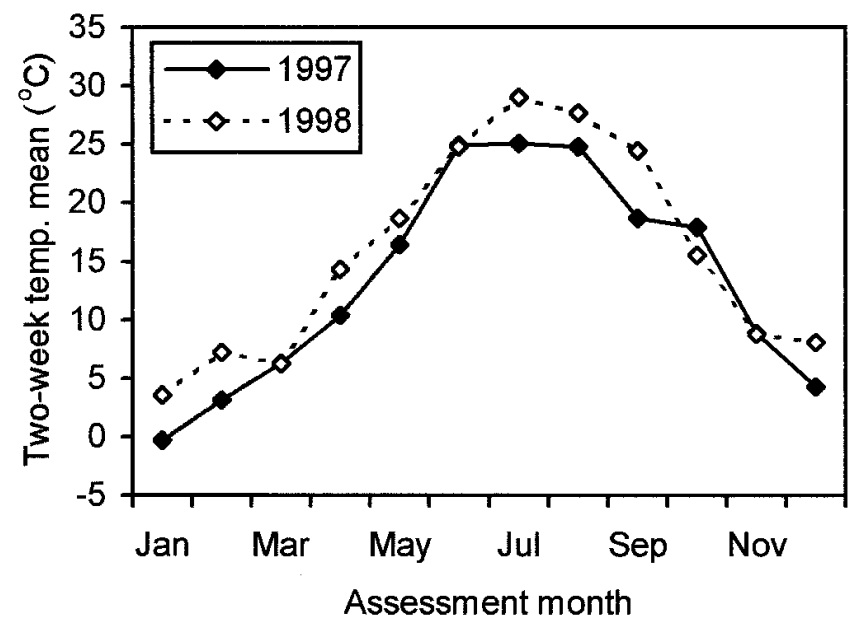

Fig. 3. Mean seasonal air temperature curves for the 1997 and 1998 test years. Data are averages of hourly temperatures recorded during the 2-week period prior to the date of canker collection in each month of the year. Data were recorded with datalogger located at a station $8 \mathrm{~km}$ from the commercial test orchard. 
Although the change in canker size followed a sinusoidal pattern during each year, the amplitude of this change did not vary greatly. This result indicated that the majority of the colonization phase occurred soon after infection, prior to formation of pycnidia. Given that the rate of colonization is a function of temperature (15), variability in fall to early winter temperature trends may explain observed variation in timing of the shoot-blight phase during the subsequent spring and summer. Warm fall and winter conditions would allow more rapid canker development and early death of shoots in spring, whereas cooler weather following infection would delay twig girdling until summer. Of course, infection periods occurring in early or later fall could also produce a similar outcome.

Once the pathogen has infected a twig, the expansion and development of that canker during its latent period is primarily dependent on temperature (15). Thus, the production of pycnidia and their maturation during this colonization phase should also be a function of temperature. Given this assumption, a canker's sporulation ability at any time should be related to the temperature conditions prior to the sporulation period. This relationship, which appeared nonlinear, was evident for both cultivars in the 1997 season. However, no such correlation was observed in 1998. One explanation for this discrepancy may be related to a difference in timing of infection during the fall. For example, if infection occurred early in fall 1997, then cankers may have been able to produce mature pycnidia sooner, allowing increased sporulation ability during the first half of 1998. Indeed, both cultivars produced greater numbers of conidia per canker during early 1998 than 1997 , even though temperatures were low during this winter period. Given these findings, any attempts to predict inoculum potential of resident cankers in an orchard will most likely have to include other variables in addition to temperature.

Emphasis in this study was placed on assessing the sporulation characteristics of the population of mature cankers over time. These cankers are the ones that would be contributing inoculum for infection. Thus, for example, when viewed as population phenomena, the canker size and pycnidia production attributes were observed to fluctuate over time. A completely different trend would have been observed had a cohort of the same cankers been assessed. Both canker expansion and pycnidia numbers would have only increased from the point of infection onward. However, this approach would not have provided information on the patho- gen's ability to produce inoculum at any time during the year. Furthermore, assessment of the pycnidia sporulation and spore production attributes necessitated destructive sampling.

The concept of pathogen compensation in relation to the carrying capacity of the environment can simply be defined as the correction of an inferiority or loss by an increased response (17). Essentially, a deficiency in one component of the disease monocycle is counterbalanced by an augmented response in another monocyclic component. Several hypotheses relating compensation to the development of epidemics (13) or evolution of fungal parasites (12) have been discussed. The results of our experiments on $P$. amygdali provide an excellent example of compensation as related to disease cycle processes. Pycnidia production in 1997, measured as number of pycnidia per canker, was approximately half of that observed in 1998 for each of the two cultivars studied. The biotic or abiotic environmental cause of this statistically significant difference across years is not known. Nevertheless, spore production in 1997, measured as number of conidia per pycnidium, was approximately twice that observed in 1998, and the difference between years for each cultivar was significant. As a result of this compensation, the number of conidia produced per canker was constant and not significantly different between years for each cultivar. Possibly, the significantly lower pycnidial densities in 1997 allowed those fruiting structures greater supply of nutrient resources from the twigs to allow increased spore production. Although this behavior was consistent across both cultivars, further experimentation is needed on other cultivars to confirm that pathogen compensation consistently occurs for $P$. amygdali on peach.

The focus in each year of this study was on sampling cankers located on 1-year-old fruit-bearing wood, those shoots produced during the prior growing season. Infections on these shoots would have been initiated the previous fall or during the ensuing spring. The resulting cankers are those that ultimately girdle the shoots, causing a direct yield loss (10) as well as provide inoculum for infection of new twig growth in the current season. No attempt was made to sample cankers on 2-year-old wood. These older cankers may provide some inoculum for infection, particularly during the subsequent spring. However, many older twigs desiccate after girdling, causing the bark to slough off and the cankers to become inactive. Thus, it appears unlikely that older cankers contribute significantly to overall inoculum production.
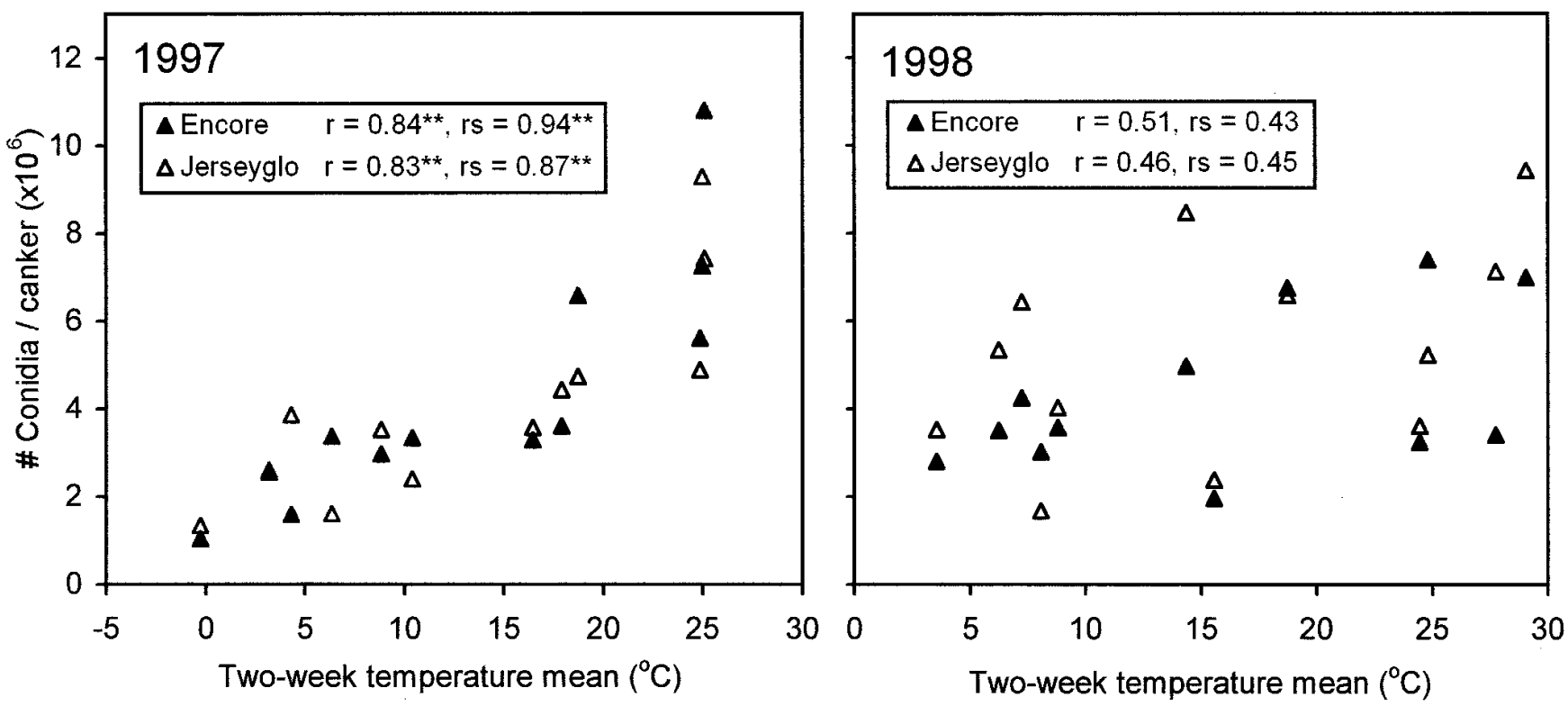

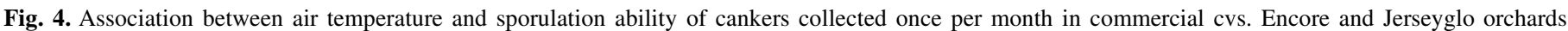

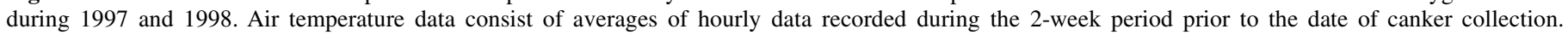

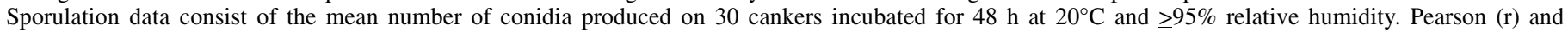
Spearman (rs) correlation coefficients were highly significant in $1997(P<0.001)$ and nonsignificant in 1998. 
The capability of pycnidia to produce conidia was greatest from June through August. Although the actual time of peak spore production varied somewhat, particularly for the 'Jerseyglo' orchard, the maximum occurred consistently within the June to August time frame. Estimating a more precise time of maximum sporulation within this 3-month period was not possible given the seasonal design of this experiment. Additional assessments, perhaps at weekly intervals, would be necessary to locate the maximum.

In contrast to our results, a recent spore trapping study showed the greatest counts of conidia from middle March to early May and again in October, with relatively low spore numbers from the middle of June to late September (16). We propose that the apparent disparity between our findings and this past study is mainly due to lack of favorable environmental conditions for sporulation during summer months. In a spore trapping study, the number of spores observed is a function of the abiotic environment as well as the number and capability of pycnidia to sporulate. In our study, all cankers were incubated under the same constant conditions favorable for sporulation. This approach allowed pycnidia, at all times of the year, to be examined and compared for their spore production potential. Nevertheless, from the viewpoint of parasitic fitness, the greatest sporulation capability during summer does not seem beneficial for species survival or evolution. However, this sporulation characteristic is consistent with the behavior of an $r$ strategist; enough effective inoculum is produced during the remaining part of the year to allow for pathogen success.

Inoculum availability for infection by $P$. amygdali is a function of canker incidence, the production and sporulation capability of mature pycnidia, and the occurrence of environmental conditions favorable for sporulation. A recent survey in moderate to severely infected New Jersey peach orchards indicated that canker incidence was high enough to result in an average of 20 to $30 \%$ yield loss (10). Very high disease incidence levels, ranging from 500 to 800 cankers per tree, were subsequently reported for two such orchards (11). These data indicate that canker incidence most likely does not limit inoculum availability in current commercial orchards. Furthermore, the results of this study show that pycnidia production and sporulation capability are most likely high enough throughout the year to allow production of sufficient inoculum for infection. Therefore, we suggest that the abiotic environment is the most critical factor governing inoculum availability for constriction canker epidemics. Studies are currently in progress to quantitatively describe $P$. amygdali sporulation on peach as influenced by various environmental parameters.

\section{ACKNOWLEDGMENTS}

This research was funded in part by the New Jersey State Horticultural Society. We thank J. F. White for his critical review of the manuscript and DeCou Hilltop Orchards for use of their peach orchards.

\section{LITERATURE CITED}

1. Biggs, A. R. 1990. Apple scab. Pages 6-9 in: Compendium of Apple and Pear Diseases. A. L. Jones and H. S. Aldwinckle, eds. The American Phytopathological Society, St. Paul, MN.

2. Cohoon, D. F., and Daines, R. H. 1954. Some facts about peach canker. Phytopathology 44:109.

3. Cohoon, D. F., and Daines, R. H. 1956. Peach canker (Fusicoccum amygdali): Times and sites of infections. Plant Dis. Rep. 40:304-308.

4. Farr, D. F., Castlebury, L. A., and Pardo-Schultheiss, R. A. 1999. Phomopsis amygdali causes peach shoot blight of cultivated peach trees in the southeastern United States. Mycologia 91:1008-1015.

5. Guba, E. F. 1953. Large leaf spot and canker of peach caused by the fungus Fusicoccum amygdali Delacr. Plant Dis. Rep. 37:560-564.

6. Guba, E. F. 1954. Fusicoccum leaf spot and canker of peach and control. Phytopathology 44:111.

7. Guba, E. F. 1955. Some historical aspects of peach canker caused by the fungus Fusicoccum amygdali Delacr. Plant Dis. Rep. 39:771-772.

8. Haenseler, C. M., and Daines, R. H. 1941. Peach canker caused by Fusicoccum amygdali. Phytopathology 31:10.

9. Lalancette, N. 1998. Availability of inoculum for Fusicoccum canker of peach. (Abstr.) Phytopathology 88:51.

10. Lalancette, N., and Polk, D. F. 2000. Estimating yield and economic loss from constriction canker of peach. Plant Dis. 84:941-946.

11. Lalancette, N., and Robison, D. M. 2000. Comparison of management strategies for constriction canker of peach. (Abstr.) Phytopathology 90(suppl.):S44.

12. Nelson, R. R. 1979. The evolution of parasitic fitness. Pages 23-46 in: Plant Disease, An Advanced Treatise, Vol. 4. How Pathogens Induce Disease. J. G. Horsfall and E. B. Cowling, eds. Academic Press, New York.

13. Rotem, J. 1978. Climatic and weather influences on epidemics. Pages 317-337 in: Plant Disease, An Advanced Treatise, Vol. 2. How Disease Develops in Populations. J. G. Horsfall and E. B. Cowling, eds. Academic Press, New York.

14. Tuset, J. J., and Portilla, M. T. 1989. Taxonomic status of Fusicoccum amygdali and Phomopsis amygdalina. Can. J. Bot. 67:1275-1280.

15. Uddin, W., and Reynolds, K. L. 1995. Phomopsis twig blight of peach: Pathogenicity and influence of temperature on disease development. (Abstr.) Phytopathology 85:1127.

16. Uddin, W., and Reynolds, K. L. 1997. Availability and dispersal of inoculum for Phomopsis shoot blight epidemics of peach. (Abstr.) Phytopathology 87(suppl.):S99.

17. Zadoks, J. C., and Schein, R. D. 1979. Epidemiology and Plant Disease Management. Oxford University Press, New York.

18. Zehr, E. I. 1995. Constriction canker. Pages 31-32 in: Compendium of Stone Fruit Diseases. J. M. Ogawa, E. I. Zehr, G. W. Bird, D. F. Ritchie, K. Uriu, and J. K. Uyemoto, eds. The American Phytopathological Society, St. Paul, MN. 